\title{
ECOLOGIA, INFECÇÃO E DOENÇA
}

\author{
Fernando Dias de Avila Pires
}

As primeiras idéias explícitas sobre relações ecológicas nos vêm dos gregos e, no tratado de Hipócrates sobre "Ares, Águas e Lugares", encontram-se os fundamentos da Ecologia Médica.

Após a Idade Média, no início da Renascença, as viagens de circumnavegação revelaram ao mundo culto europeu a existência de animais, plantas e homens estranhos, vivendo em "habitats" distintos daqueles conhecidos no Velho Mundo. Naturalistas viajantes acumularam descrições, informações e dados novos que, liberados das fantasias e triados convenientemente, passaram a exigir a reformulação dos conceitos então vigentes sobre a organização do mundo animal e vegetal e suas relações com o ambiente.

O Renascimento introduziu profundas reformas no pensamento e na metodologia de trabalho científico. A invenção do microscópio, no século XVII, permitiu descobrir e explorar o mundo microbiano. A teoria celular, a sintese da matéria orgânica e a demonstração, por Liebig e Wôhler, do papel da heterotrofia na fisiologia das plantas, e, em conseqüência, da adubação mineral para a agricultura, prepararam o caminho para a revoluçāo conceitual que se processou no século XIX.

$\mathrm{Na}$ segunda metade do século passado, Charles Darwin e Alfred Russel Wallace (15) anunciaram os princípios fundamentais que regem as relações recíprocas en- tre os organismos e o ambiente e identificaram os fatores responsáveis pelo equilíbrio natural e pela evolução orgânica. Ambos tiveram a atenção despertada para o problema pela leitura de um ensaio escrito por Malthus em $1789(39,40)$. Thomas R. Malthus foi um dos pioneiros no campo da Demografia e da Biometria que, juntamente com a Estatística, servem de base ao estudo da Dinâmica de Populações ou Autoecologia Numérica.

Competição, adaptação e seleção natural emergiram como conceitos básicos de um sistema natural e filosófico, cujas implicações foram exploradas e desenvolvidas - e muitas vezes destorcidas - por biólogos, sociólogos, filósofos, teólogos, economistas e políticos.

Divulgador das idéias de Darwin e Wallace, Ernest Haeckel considerava a adaptação e a hereditariedade como as duas grandes leis governantes da organização vital. E, em 1866, propôs o termo Ecologia para designar o estudo das relações dos organismos com o ambiente (32). Em sua "História da Criação" (33), entre as provas da validade da teoria de Darwin, cita:

" $L$ 'ascologie ou distribution géographique des organismes, la science de l'ensemble des rapports des organismes avec le monde extérieur ambiant, avec les conditions organiques et anorganiques de l'éxistence; ce qu'on apelle l'économie de la

* Professor Adjunto, Departamento de Vertebrados, Museu Nacional, Universidade Federal do Rio de Ja. nelro; Professor de Ecologia do Curso de Pós Graduaçấo em Doenças Infectuosas e Parasitárias da Faculdade de Medicina da mesma Universidade; Diretor Executivo da Fundaçäo Brasilelra para a Conservaçáo da natureza.

Recebido para publicaçáo em 15.3.1974. 
nature, les mutuelles relations de tous les organismes, vivant en un seul let même lieu, leur adaptation au milieu qui les environne, leur transformation par la lutte pour vivre, sourtout, les phénomènes du parasitisme, etc. Précisément ces faits d'économie de la nature... résultent nécessairement des causes mécaniques. Ce sont des faits d'adaptation."

Os dois tipos fundamentais de interações ecológicas: de organismos com o ambiente físico (ecotópicas) e die organismos entre si (alelobióticas) serviram de base às duas grandes teorias evolucionistas do século passado (4).

Lamarck $(37,38)$ foi autor da primieira teoria, pioneiro em sugerir um mecanismo natural para explicar o fenômeno da evolução ou "transformismo" _ como se preferia dizer, na época - e que admitia a herança das alterações orgânicas somáticas ou fenotípicas sofridas por influência direta do ambiente e em decorrência do uso ou não uso dos órgãos. Atribuia destacada importância às influências mesológicas - ecotópicas - especialmente sobre as plantas e animais "inferiores".

Darwin (15) propôs uma teoria coerente e muito bem documentada, que ressaltava, por outro lado, o papel das relações alelobióticas reguladas pela ação da seleção natural, a qual seria o mecanismo fundamental e diretor da evolução orgânica. Admitiu, também, em certa medida (mais enfaticamente nas primeiras edições da "Origem das Espécies") a herança do tipo "lamarckiano", influenciado que foi pela leitura da "Filosofia Zoológica" de Lamarck, quando, a bordo do veleiro Beagle, reunia as primeiras notas e impressões para sua própria obra (4).

Darwin discutiu, em detalhe, o problema das adaptações interespecificas e da competição intraespecífica, ao expandir sua teoria em obras posteriores.

Caberia a Mendel (45), cujas idéias só tiveram ampla divulgação após a "descoberta" e tradução de seu trabalho, a partir de 1900 , reunir os dados experimentais que permitiram refutar a hipótese da herança de modificaçõies somáticas, adaptativas ou não, e resumir, em duas leis, os princípios da hereditariedade.

Contudo; os estudos sobre as influências ambientais e as relações entre orga- nismos prosseguiram com êxito e deram origem à Ecologia moderna. $\mathrm{Na}$ década de 1920, paleontólogos, taxonomistas e geneticistas reuniram para estabelecer as bases de uma nova teoria - "néodarwinista" da evolução, plasmada nos mecanismos da herança mendeliana e fundamentada na moderna genética, na bioquímica e na biologia celular, que revelaram a origem das variações. Admite a "teoria sintética", a seleção natural como mecanismo criador, que age através da seleção de fenótipos (e genótipos) mais viáveis, levada a efieito pelos fatores do ambiente físico e do meio biótico $(16,31,35,36,42,54,56,60,63)$.

Em sua essência, tanto a hipótese lamarckista quanto a de Darwin baseavam-se na ação decisiva do ambiente: Lamarck, advogando a idéia da influência direta do meio físico como causa da variação individual e específica e, portanto, da evolução dos organismos; Darwin e Wallace defendendo a prioridade da competição e da seleção natural, sobre variaçōes individuais e específicas, cuja ocorrência admitiam como postulado e sobre cuja origem não possuam idéia perfeitamente definida.

Sucederam-se, em conseqüência, trabalhos sobre etologia e ecologia, a princípio com abordagem informal, pouco metódica e muito desordenada, descrevendo o conjunto de fenômenos que foram, finalmente, integrados em um campo científico autônomo. Mimetismo, parasitismo, sinúsias, polinização cruzada e outros tipos de relaçōes bióticas, que incluem a antibiose e 0 amensalismo possuem um denominador comum quando analisados do ponto de vista ecológico.

Darwin, Wallace, Bates, Pasteur e outros abriram caminho a novas pesquisas e estabeleceram a metodologia apropriada à ordenação das idéias numa nova linha de investigações.

O papel e a importância das relaçōes de competição e de cooperação na Biosfera foram logo reconhecidas, mas devido ao impacto social das obras de Malthus, Darwin, spencer e Wallace, a "luta pela viđa" e a competição seletiva receberam mais atenção que as relações de cooperação entre organismos $(3,22)$.

Com o início das investigações sobre dinâmica e equilíbrio de populações silvestres voltou-se a discutir a prioridade 
dos fatores bióticos (competição, predação, parasitismo, amensalismo) e abióticos (clima) na estabilidade das comunidades. Na verdade, estão eles de tal forma correlacionados que é difícil considerar isoladamente a ação de cada um. Como sóe acontecer, a razão encontra-se dividida entre os argumentos cics defensores de ambas as hipóteses.

A idéia de associação biótica data dos gregos, mas existiu, informal e empírica, desde a mais remota antiguidade, como existe entre índios e caçadores. Em sua concepção moderna, foi formulada na década de 1830 . Forbes $(24,25)$ foi o autor da primeira conceituação precisa de biocenose e, em 1877, Möbius (46) lançou os fundamentos da Ecologia contemporânea, ao descrever a estrutura e a dinâmica de uma comunidade de ostras. Em 1939, Clemens e Shelford (10) estabeleceram o conceito de bioma como um "organismo social".

Schroter (56) propôs os termos autoecologia, em 1896 e sinecologia, em 1902 , para designar os dois niveis de complexidade em que se desenvolvem os fenômenos ecológicos: enquanto que o primeiro trata de populações de uma única espécie, o segundo refere-se à ecologia de comunidades e ao equilíbrio biológico dos ecosistemas. No nivel individual, ecologia confunde-se com fisiologia, etologia, e psicologia. Segundo Chapman (11) "In the study of autoecology it is quite evidient that the work is bordering very closely on the field of physiology". Esse autor, aliás, só reconhece o estudo das comunidades como sendo verdadeiramente ecológico.

Shelford (56) tinha cpinião semelhante, porquanto definiu: "Ecology is that branch of general physiology which deals with the organism as a whole, with its general life processes as distinguished from the more special physiology of the organs, and which also considers the organism with particular reference to its usual environment."

$\mathrm{Na}$ verdade, exprimiram ambos os autores citados a idéia de que o funcionamento ou fisiologia de órgãos, organismos ou populações merecem um lugar de des- taque e têm muito em comum como fenômenos biológicos.

Entretanto, na escala de complexidade dos níveis de integração, os órgãos são um degrau intermediário e as populaçōss, subdivisāo das comunidades e não têm existência independente, de vez que nenhum organismo vive isolado.

A comunidade biótica ou biota é a unidade funcional no nivel do ecosistema, isto é, da Sinecologia (*).

Toda comunidade estrutura-se em niveis tróficos, cujo número é limitado pela perda de energia considerável que se verifica na passagem de um nivel a outro. $\mathrm{Na}$ base do sistema estão os organismos clorofilados, que fixam energia solar e sintetizam compostos orgânicos a partir de elementos minerais do substrato, por fotossintese; em sucessão vertical estratificam-se os organismos fitófagos (microorganismos, vertebrados e invertebrados erbivoros e plantas parasitas aclorofiladas), os pequenos carnivoros (incluindo os insetívoros, vertebrados e invertebrados que se alimentam de proteína animal, caçando a presa), os grandes predadores e os parasitos; ao lado, os saprófitos ou decompositores, que fazem retornar ao substrato, desagregada em seus radicais inorgânicos, a matéria orgânica morta, para reiniciar-se o siclo que constitui a teia da vida.

Produtores e consumidores, animais e plantas, macro e microrganismos, competem e cooperam direta ou indiretamente no processo de exploração dos distintos nichos ecológicos - que são as oportunidades abertas à sua existência, dentro da estrutura trófica $(* *)$.

Numa comunidade, para que o sistema de transferência de nutrientes e transformação de energia se mantenha, devem-se preservar os nichos, não importa que espécie (ou taxa) os ocupem. Dessa forma, se queremos eliminar uma espécie que nos causa problemas sanitários ou econômicos, devemos procurar alterar o ecossistema, a fim de fazer desaparecer o nicho que explora - ou então, tentar substituílo por outra, inócua, após reduzir seu número.

O fenômeno do vicarismo fundamenta-se nesse fato, isto é, na 'equivalência ecológica, que permite a espécies muito dis-

* O deme constitul a unidade no nivel social, populacional ou da Autoecologia (9, 29, 35)

* Muitos autores confundem nicho com microhabitat. Nicho é funcional, enquanto microhabitat é espacial ou estrutural (21). 
tintas ocuparem um mesmo nicho, em regiōes diferentes $(20,43)$.

A competição, que pode ser interespecífica ou intraespecifica, reveste-se de formas várias, nem sempre ativas e de imediato apercebidas por nós, nem dramáticas como o termo sugere. Pode traduzir-se na taxa de reprodução diferencial, na taxa de reposição, no amensalismo e antibiose, na preferência alimentar, na taxa de metabolização diferencial, na valência ecológica, na disputa de locais para abrigo e no comportamento territorial.

Fischer (23), Wright (68), D'Ancona (13) e outros dedicaram-se a investigar os aspectos matemáticos da seleção natural, demonstrando que pequenas vantagens sejetivas podem resultar na sobrevivência de uma população e no desaparecimento de outra.

A cooperação resulta em que podem advir de associaçōes de tipos vários, que vão desde o frouxo grupamento acidental ou agregado ocasional ou temporário de indivíduos independentes ou pertencentes a espécies distintas, à organização familiar, com a transmissão de elementos culturais adquiridos, e à coexistência necessária e indispensável dos simbiontes estritos $(3,22,53)$.

Ao sistema de transferência e circulação de nutrientes e de transformação de energia, aberto do ponto de vista termodinâmico, autorregulável ou homeostático, e relativamente estável no tempo, fruto da evolução biogeodinâmica do Terra, dá-se o nome de ecossistema ou biogeocenose (65).

O funcionamento de um ecossistema pode ser estudado em uma floresta, em um tronco apodrecido, em um cupinzeiro, em um lago ou em um aquário (26). Do mesmo modo, o corpo de cada animal abriga uma microbiota comensal, simbionte e parasita e constitui um ecossistema (12, 17, $18,19,41,54)$.

A idéia da dualidade microcosmo/macrocosmo foi introduzida na filosofia ocidental por Alcmeon de Crota (500 A.C.) e incorporada aos sistemas das Escolas Pitagórica, Atomística e Epicurista.

Singer (59), discutindo as influências orientais no pensamento ocidental, registra que o judeu Donolo dedicou-se ao estudo dos conhecimentos árabes, quando prisioneiro dos sarracenos e, em seu "Livro da Criação", publicado em 946, desenvolveu a "antiga doutrina encontrada no Timaeus, (de Platão), de macrocosmo e microcosmo ou paralelismo entre o meio exterior da natureza e o meio interior do corpo humano, idéia muito popular entre os autores árabes".

Seneca, Alberto Magno, Paracelso, Roberto Boyle, Leibnitz, Harvey Oken, Goethe e muitos outros foram seus adeptos.

Nos ecossistemas, essa concepção dualista é real. Em um bioma como a savana, o macroclima condiciona a existência de comunidades próprias ou características; em cada biótopo, o mesoclima cria condições particulares e nos microhabitates, o microclima faz o mesmo. Um cupinzeiro constitui um pequeno mundo à parte, onde cupins e seus comensais exógenos compartilham das condições específicas de temperatura, umidade, iluminação prevalentes, e ali cooperam e competem em um microecossistema independente, em boa medida, daquele do biótopo em que se situa, no meio da savana.

Dessa maneira formam-se ecossistemas dentro de ecossistemas, como círculos dentro de círculos $(28,51,64)$.

Do mesmo modo, o corpo de um animal oferece microhabitates especiais, com microclismas próprios, onde vivem microorganismos saprófitos, simbiontes, comensais, parasitos, os quais constituem a microbiota individual.

O estudo da distribuição geográfica e ecológica dessas comunidades é complicado pelo fato de termos que levar em conta os padrōes biogeográficos da Biosfera e padrões microgeográficos dentro do habitat, isto é, do corpo do hospedeiro que as abriga. Sua distribuição geográfica é in'fluenciada pela dos hospedeiros e a história paleogeográfica de ambos está intimamente relacionada (46). essa história que determina o grau de endemismo ou cosmopolitismo da espécie $(* * *)$.

Dubos $(17,19)$ considera como parte da microbiota indigena:

a) microorganismos simbiontes, que evoluiram no hospedeiro e que recebem a designicação de autóctones por essa razão.

* * Hershkovitz (34) asstnala que endêmico nāo deve ser empregado para taxa de categoria Inferior a espécie, como seja a um deme ou populaçāo local. Assim é vedado seu uso em termos de microhabitates. 
b) microorganismos que podem estabelecer-se em diferentes tecidos e viver em saprofitismo ou comensalismo e que podem, sob certas circunstâncias, mostrar-se patogênicos.

c) microorganismos presentes na maioria dos indivíduos que habitam uma região ou localidade e que constituem a microbiota normal. Entre estes, pode haver patógenos como acontece com o Plasmodium em certas partes da África e Nova Guiné, e com virus respiratórios, nas grandes cidades. A “diarréia dos viajantes" é provocada pela modificação da microbiota normal.

A distinção entre os componentes dos grupos $a$ e $b$ não é fácil de se fazer e mesmo os simbiontes podem mostrar-se patogênicos, em certas situações.

O local ou região em que se originou e evoluiu um taxon (centro de origem) contribui para determinar a região ou local que habita. Mas suas exigências ecológicas fazem o mesmo. Assim, um paleontólogo e um ecólogo podem utilizar a mesma terminologia mas com sentidos distintos.

Simpson (61) define nativo como sendo o grupo ou taxon que vive naturalmente em uma região, e não por introdução proposital ou acidental; e autóctone como aquele que se originou, por evolução, na região em que vive - conceitos esses adotados por Dubos.

Mas Hershkovitz (34) sinonimiza nativo, autóctone e indigena com o sentido de autóctone de Simpson.

Dada a dificuldade de se determinar tanto o hospedeiro como o microhabitat em que se originaram comensais, parasitos e simbiontes que nos interessam, deve-se restringir o uso de autóctone aos casos evidentes em que a especificidade e o grau de adaptação ao hospedeiro indiquem a origem evolutiva de um taxon de microorganismos. Pode-se admitir que simbiontes estritos e parasitos profundamente modificados tenham sofrido longo processo de adaptação ao hospedeiro, mas nem sempre é fácil reconhecer o grau de evolução da associação. Não se pode ignorar a possibilidade de substituição de um simbionte por um vicariante, que se aproveita de um nicho ecológico ocasionalmente vazio.

Indigena e nativo devem ser considerados sinônimos: traduzem o grau de inti- midade da adaptação da microbiota ao hospedeiro.

Em termos de microgeografia, Hershkovitz (34) chama de regionalista um taxon nativo em uma região, à qual pode estar confinado (endêmico) ou de onde partiu para invadir e colonizar outra área, geralmente contigua (excurrente). Em termos de microgeografia, vedado o uso de endêmico para unidades taxonômicas infraespecíficas, e levando em consideração que a localização ou ubiquidade de um microorganismo no hospedeiro depende da espécie deste, podemos utilizar os termos euriético para os microbiontes ubíquos ou não em termos de microclima e estenoecio para os limites.

Aparelho digestório, aparelho circulatório, trato respiratório, dobras da epiderme constituem alguns dos microhabitates principais, nos vertebrados, e abrigam comunidades caracteristicas, cujas estruturas repetem as dos ecossistemas externos e cuja dinâmica depende de fatores ecológicos semelhantes aos que condicionam os grandes biomas: temperatura, luz, umidade, pH, velocidade de fluxo, tensão osmótica, gravidade, que variam em escala milimétrica ou micrométrica no corpo do hospedeiro.

Essas microbiotas ou microcomunidades podem sofrer desequilibrios em virtude de alteraçōes que se verificam nas condições "ambientais", isto é, do corpo que as abriga; podem sofrer a competição de espécies imigrantes ou excurrentes ( exógenas) ou terem seu equilíbrio comprometido pela extinção ou redução das populações de certos componentes da microbiota individual, com reflexos no equilíbrio ecotópico, que desencadeia efeitos físiológicos recíprocos. $\mathrm{O}$ uso de antibióticos, raios $\mathrm{X}$ e corticosteroides provoca tais resultados. Segundo Alexander "There is little doubt that numerous pathogen flare-ups occur in direct response to a lowering of the body's defense mechanisms, but it is likey, too, that the cause is frequently a disturbance in the balance among the indigenous microbial populations."

Bactérias como Escherichia, Alcaligenes, Proteus, Pseudomonas, Staphylococus e as do grupo Klebsiella-Aerobacter não eram consideradas particularmente patogênicas antes da era dos antibióticos e hoje provocam bacteremias e infecçōes clínicas em 
pacientes submetidos a tratamentos com antibióticos.

A patogênese não constitui um atributo, mas uma circunstância. Depende da espécie do hospedeiro, isto é, de respostas específicas dos diferentes hospedeiros a um mesmo parasito, de fatores momentâneos como o stress, de condições do microbiótopo que o microorganismo invade ou ocupa, como no caso da febre reumática, de meningoencefalites, de tuberculoses, ou de certos tecidos onde o invasor se multiplica ou enquista, e, ainda, da ação inibidora ou modificadora (fagos, p.ex.) de outros microorganismos.

Deve-se notar que as definições de parasitismo e de associações mutualísticas que levam em conta possiveis benefícios ou prejuízos causados aos hospedeiros ou parceiros, pecam pela base. Os conceitos de bom e mau são humanos e morais e variam com o lugar, a época e a ocasião. Além disso, na natureza não existe bem ou mal intrínsecos. O parasito ou predador que funciona como agente de controle demográfico de uma população de hospedeiros ou presas sacrifica certos indivíduos, mas contribui para assegurar a sobrevivência $\mathrm{da}$ população $\mathrm{em}$ boas condições sanitárias e em equilíbrio com os recursos tróficos e espaciais da área. Como ressalta Stallones (62), a assistência médica individual tem, na maioria dos casos, pouca relação com a melhoria das condições de saúde pública. Além disso, cria certos problemas sociais como a preservação de gens deletérios, aumento da incidência de certas enfermidades da velhice, e problemas relativos à superpopulação.

$O$ estudo das microcomunidades individuais obedece aos mesmos princípios que regem o das comunidades exógenas. Os desequilíbrios que afetam as condições sanitárias desses microorganismos são objeto de investigação de uma "microepizootiologia". Como acarretam alterações no "ambiente" ou hospedeiro, podemos usar o termo microepidemiologia ou autoepidemiologia, quando a preocupação fundamental é focalizada em sua ecologia.

A Patologia pode ser estudada em todos os níveis de complexidade biológica: o histopatologista preocupa-se com as altera- ções que se verificam nos níveis celular e orgânico; o clínico no nivel organismal ou individual; o médico previdenciário faz medicina social e ocupacional, e o epidemiólogo cuida dos problemas médico-sanitários ao nível do ecossistema, isto é, da ecclogia médico-sanitária $(* * *)$.

Sob o título de "Ecologia das doenças" dois aspectos distintos devem ser considerados separadamente, mas são, em geral, confundidos. Em primeiro lugar, podie-se estudar a autoscolcgia dos agentes: seu ciclo biológico, suas exigências em termos de condições ambiente, seus rítmos, seu comportamento. Em segundo lugar, podemos pesquisar a ecologia da transmissão, o que envolve a investigação das relações parasito/hospedeiro e dos fatores que contribuem para a infecção daquele, incluindo contingências sócio-econômicas e outras.

Exemplificando, podemos estudar o compcrtamento ecológico das filárias, seu ciclo cincadiano e os fatores que o condicionam. Por outro lado, em termos de sinecologia, investigamos o complexo de relações dos hospedeiros com os mosquitos transmissores. O estudo da ecologia da peste envolve, por um lado, a investigação da autoecologia de pulgas, de roedores e de bactérias, por outro, das condições resultantes da associação dos três, nos distintos biótopos onde se encontram juntos, dentro das respectivas áreas de distribuição geográfica. Assim, em alguns lugares a peste se manifesta como um problema urbano, em outros é ruderal e pode ser, em certas áreas, um problema ocupacional.

Elton foi um dos pioneiros na pesquisa dos aspectos ecológicos das epizootias e epidemias e, em Golvan e Roux (30), encontramos exemplo recente de trabalho meticuloso e detalhado nesse campo especializado da Ecologia.

A Ecologia Médica é uma disciplina jovem, apesar de ter suas raizes mergulhadas na escola de Cós.

Sua premissa básica é a homeostase ambiente, onde o equilibrio natural depende de um sincretismo ecológico e a saúde traduz o ponto de equilíbrio: esta resulta, portanto, de um ajuste homeostático do organismo com o meio em que vive. çaz não Infeeciosas, em autoecologia médieo-sanitária 
Para os ecólogos, infecção é um aspecto particular dos fenômenos da alelobiose e da ecobiose $(* * * *)$ quando envolvem microorganismos e macroorganismos. Resulta da ocupação de um microhabitate em um organismo hospedeiro por um microorganismo invasor ou colonizador, o que explica a presença ocasional de microorganismos de vida livre no corpo de hospedeiros fortuitos. As relaçôes entre eles podem ser hcrmônicas ou desarmônicas, conforme o local de entrada, o inóculo, a virulência do invasor, a resistência orgânica e o estado de stress ou tensão do hospedeiro (que pode autoagredir-se), as reaçöes de outros elementos da microbiota já instalados, e de circunstâncias diversas ou fatores que atuam no macroambiente e nos microhabitantes do organis mo.

Dependendo do grau de especificidade parasitária (52) e das relações entre hospedeiro e parasito, o resultado pode ser variável.

A Geografia Médica pode ser estudada, igualmente, na escala do macrocosmo e do microcosmo.

A coincidência de certos padrões biogeográficos com os de ocorrência de algumas zoonoses levou à teoria da focalização: esta nađa mais é que a tradução, em termos médico-sanitários ou epidemiológicos dos conceitos de biogeografia ecơlógica desenvolvidos no último século. Pavlovsky formulou, em 1939, a teoria da nidalidade natural das zoonoses, em termos de biocenoses (50). Segundo Galuzo (27) "O nascimento da teoria da nidalidade natural de doenças é uma prova da fecundidade do terreno entre dois campos ou disciplinas científicas - uma área onde, como sucede entre dois polos elétricos, uma fagulha ilumina um ncvo caminho." Galuzo cita Pavlovsky, que afirma que o problema das zoonoses deve ser "investigado à base de pesquisas zoológicas, parasitológicas, combinadas com projetos de natureza microbiológica e com a participação de epidemiólogos", o que a organização Mundial de Saúde recomendou, para os estudos no campo da peste (49).

Como sucedeu com a Biogeografia em seus primórdios, o estudo da microdis- tribuição e da ecologia de parasitos, em relação aos hospedeiros é dificultado pela falta de dados e observações precisos (2).

Antes do desenvolvimento da teoria moderna da evolução orgânica, que atribuiu importância capital ao isolamento geográfico como fator de especiação $(42,61)$, pouca atenção era dada à procedência exata de espécimes coletados para estudos sistemáticos. Wallace e Agassiz inauguraram uma nova era: Agassiz, fixista, paradoxalmente contribuiu para o esclarecimento de muitos pontos obscuros da teoria Evolucionista (5). Em 1865, a bordo do navio que trouxe os membros de sua expedição ao Brasil (1), traçou os rumos das pesquisas zoogeográficas que deveriam ser desenvolvidas, ao ressaltar: "Quando se conheciam menos coisas sobre as plantas e os animais, a descoberta de uma nova espécie era um objetivo importante. Levol-se tão longe essa investigação que, hoje, é quase a menos útil que se pode fazer... Devemos interessar-nos de preferência pelas relações fundamentais que existem entre os seres; as espécies novas que encontrarmos só terão importância com a condição de lançar um pouco de luz sobre a distribuição e a limitação dos diferentes gêneros e famílias, seus laços comuns e suas relações com 0 ambiente físico onde vivem... O nosso primeiro passo nessas questões deve ser determinar exatamente a distribuição geográfica das plantas e animais atuais... Cinqüenta anos atrás, precisar exatamente o local donde um dado animal provinha parecia uma coisa absolutamente sem importância para a história natural desse animal, uma vez que ainda não se percebia a importância disso para a descoberta de sua origem. Dizer que um peixe provinha da Américá do Sul era então tido como suficiente, e especificar 'se vinha do Brasil ou do Prata, de São Francisco ou do Amazonas, parecia um luxo para o observador... Tais indicaçōes são por demais vagas para o fim que temos em vista. Nosso trabalho exige muito mais precisão."

Crompton (12), ao estudar a distribuição microgeográfica de helmintos parasi-

\footnotetext{
**** Alelobiose é o termo usado por Mello Leităo (44) para designar as relaçóes entre espécies. Eco. blose fol proposto por Huxley (35) para designar adaptaḉo a um modo de viaa particular ou nicho. Em grande extensão, ambos os termos sáo sinônimos porém, em certos casos, existe diferença em especial no que tcoa aos produtores primários ou vegetaís clorofilados.
} 
tos do trato alimentar de vertebrados, transpôs para a escala microcósmica os problemas da biogeografia ecológica. Referiu-se a um estudo pioneiro de Neumann (48) que reconhecia, em 1892, que: "De ces divers groupes, il en est dont les réprésentants sont localisés presque absolutement dans un compartiment déterminé de l'appareil digestif." E, em seguida, comenta que "Desafortunadamente, muitos helmintologistas têm ignorado o significado dessa generalização e a ecologia dos helmintos tem sido descurada. Além disso, realizam-se estudos de helmintos in vitro, sem o equivalente aos cuidados adotados em observações de campo, como base para a experimentação .... O conhecimento exato da distribuição dos helmintos (no trato alimentar dos vertebrados) deverá proporcionar melhor compreensão dos fatores que afetam a densidade populacional, nutrição, crescimento, reprodução e outros aspectos de sua biologia. ... Descrição exata dos sítios ocupados por helmintos são fundamentais para a nossa compreensão de sua ecologia. No passado, muitos taxonomistas assinalavam a localização de um helminto como "intestino", a despeito das instruções de Barun e Lühe (8) que afirmavam que muitas espécies localizam-se em seções particulares do intestino delgado e que a distribuição indistinta da mesma espécie ao longo de toda a extensão do intestino cielgado é raramente verificada em hospedeiros mortos recentemente. Alguns autores responsáveis por descriçōes inacuradas receberam material já fixado, retirado do hospedeiro, porém investigadores futuros que coletam espécimes pessoalmente, devem realizar descrições cuidadosas. Informação sobre sitios (microbiótopos) nunca será conseguida se o intestino delgado é "expremido e esvasiado, e seu conteúdo lavado e recolhido em um recipiente", como apresentado em estudo muito recente, publicado sobre 154 hospedeiros. Ideal seria incluir as seguintes informações, além dos detalhes sobre idade e sexo do hospideiro: 1) distribuição linear do parasito; 2, distribuição radial do parasito; 3 ) tempo decorrido entre a morte do hospedeiro e a coleta do parasito; 4)) hora em que a coleta foi realizada; 5) o estádio da digestāo em progresso no momento da morte do hospedeiro; 6) a estação do ano quando os parasitos foram colhidos; 7) o estadio reprodutivo do parasito; 8) detalhes sobre a carga parasitária e outros parasitos presentes no trato alimentar do hospedeiro. Não se devem fazer descrições e generalizações à base de poucos parasitos e poucos hospedeiros.

Existe, assim, um largo campo aberto à investigação: a ecologia das biocenoses que os animais abrigam e as interrelaçōes dessas comunidades endógenas com o hospedeiro.

Vimos, de passagem, que sob certas circunstâncias verificam-se desequilíbrios entre parasitos ou "agentes infectuosos", e o organismo hospedeiro. Esses desequilíbrios produzem sintomas característicos, que são devidos ora à ação de toxinas produzidas pelos microorganismos, ora à própria resposta do hospedeiro, em auto-agressão.

Tais sintomas, quando clinicamente detectáveis, caracterizam as doenças infectuosas e parasitárias. Entretanto, os limites entre o estado de infecção subclínica ou inaparente e o de enfermidade declarada são convencionais e dependem das facilidades de diagnóstico à disposição.

À medida que o conhecimento do comportamento da infecção progride e o arsenal de instrumentos e drogas se aperfeiçoa, mais refinado, seguro e precoce torna-se o diagnóstico e novos padrões são estabelecidos para tratamento.

Para o ecólogo, a doença é qualquer alteração morfológica ou funcional que compromete a sobrevivência de um indivíduo em seu ambiente natural.

Para o clínico, a infecção só interessa quando pode ser detectada pelos métodos diagnósticos correntes. Mas para o geneticista aplicado, o sanitarista e o epidemiólogo, que laboram no nivel social ou no do ecossistema, o portador inaparente é mais importante e o paciente declarado está fora de sua jurisdição, a não ser como dado estatístico e indicador. Para o ecólogo, o doente não importa, mas sim a doença como um sintoma de desequilibrio no ecossistema.

Do ponto de vista evolutivo, admite-se que a infecção parasitária origina-se da colonização de um microhabitat, no corpo de um animal, por organismos de vida livre, que encontram alí condições semelhantes às de seu habitat normal. As con- 
dições finais são o comensalismo e a simbiose sensu strictu $(* * * * * *)$.

Para Alexander (2), "Infectious disease represents a category of population/environment interactions involving a host plus a microorganism with the potential for both colonization and pathogenesis."

Do ponto de vista ecológico, a condição de endemia inđica uma faixa de equilíbrio, enquanto que a epidemia (e epizootia) traduz pərturbações na homeostase da biogeocenose.

Um século após o início da era inaugurada por Pasteur e Koch podemos avaliar, com mais segurança, o impacto causado pela comprovação da teoria da origem microbiana das infecçōes.

Como conseqüência imediatamente positiva, contamos o nascimento e evolução vertiginosa das disciplinas microbiológicas, as quais pouco teriam progredido se interessadas apenas no estudo acadêmico ou fundamental do mundo microbiano. Impulsionadas pelo interesse imediato e pelas perspectivas de aplicação a problemas de suma importância individual, social e econômica, as pesquisas na área da microbiologia médica, veterinária, agrícola e industrial avançaram de maneira notável, dominando o panorama científico do final do século passado e do início do século $\mathrm{XX}$. A investigação dos "agentes causais" passou a ser considerada a meta prioritária da medicina, em todos os seus níveis. $O$ aprimoramento das técnicas de labcratório reverteu em proveito da pesquisa, que se ampliou em extensão e escopo. A medicina como arte passou a sofrer competição por parte da ciência médica: a arte de curar cedeu, pouco a pouco, lugar à técnica de diagnosticar e à segurança e precisão no prescrever, graças ao auxílio do laboratório.

Após a Primeira Guerra Mundial, os problemas de epidemiologia propuseram novos desafios aos pesquisadores e administradores. A Segunda Guerra Mundial tornou esses desafios em demandas urgentes. As revoluções sociais que se iniciaram traziam revelações desconcertantes. As transformações provocadas pela facilidade de comunicação e transporte, que culminaria na panmixia potencial da "aldeia global" expôs novos problemas cruciais, ưue não podiam ser reduzidos à simplicidade da proveta, da placa de petri e do microscópio.

Entre a solução ou informação teórica e a aplicação prática, em escala mundial ou, mesmo, continental ou nacional, vai grande distância e a descoberta ou invenção de métodos capazes de permitir-nos atuar na escala que possibilite prevenir ou controlar uma epizootia ou epidemia vale tanto (às vezes mais) que a descoberta de seu agente etiológico.

Os problemas de superpopulação, de aumento do contingente de enfermidades gerontológicas e de preservação de gens deletérios exigem a tomada de posiçōes novas. Por outro lado, a assistência individual não garante a saúde pública (62) e acarreta maiores responsabilidades sociais.

Pouco a pouco firma-se a idéia de que a teoria da agência causal, determinística, é simplista e reducionista.

Durante a Segunda Guerra Mundial, as pesquisas sobre a epidemiologia do tifo, da tuberculose e da malária vieram mostrar a importância da investigação dos complexos causais ou complexos de relações ecológicas como base dos programas de vigilância e controle de proiblemas médico-sanitários. As pesquisas sobre zoonoses deram maior ênfase à componente ambiental. A evolução da Ecologia trouxe novos elementos conceituais para esclarecer dúvidas e colocar uma nova problemática em foco.

Em parte, foi a fragmentação das especialidades, compartimentando, por força da necessidade de especialização profissional, os cursos de formação, o responsável pela evolução divergente ou paralela das ciências biológicas e biomédicas.

A reintegração de conceitos desenvolvidos isoladamente e a aplicação reciproca de metodologia e técnica sempre foi fonte de progresso súbito. Mas Clemens e Shelford (10) advertem que "students of ecology will continue to be trained primarily as botanists, zoologists, sociologists, or economists for some time to come - presumably indeed as Iong as University departments are organized on the present basis." 
Ao mesmo tempo, a investigação da ecologia das doenças deve ser feita de maneira a permitir formar uma imagem da complexidade dos processos envolvidos e das condições de sua ocorrência; para isso é necessário conhecer o comportamento, a dinâmica $e$ as relações dos diversos componentes das biocenoses e patocenoses, quando em equilíbrio, para podermos isolar os fatores condicionantes dos desequilíbrios que traduzem a doença, a epidemia e a epizootia.

\section{REFERÊNCLAS BIBLIOGRÁFICAS}

1. AGASSIZ, L. \& AGASSIZ, E.C., $1869-$ Viagem ao Brasil 1865-1866. Tradução e notas de E. Sussekind de Mendonça. Brasiliana, Cia. Edit. Nac., 1938, São Paulo.

2. ALEXANDER, M. - Microbial Ecology. John Wiley \& Sons, N. York, 1971.

3. ALLEE, W.C., - Cooperation Among Animals. Henry Schumann, N. York, 1957 :

4. ÁVILA-PIRES, F.D. - Seleção Natural: Centenário da Comunicação de Darwin e Wallace sobre a seleção Natural. Publ. Avul. Mus. Nac., Rio de Janeiro, 46: 1963.

5. AVILA-PIRES, F.D. - A contribuição de Louis Agassiz à Biologia. Atas Soc. Biol. Rio de Janeiro. 9: 17-21, 1965 .

6. AVILA-PIRES, F.D. - The evolution of protective resemblances. An. Acad. Brasil. Ciênc., 40: 101-103, 1968.

7. BATES, H.W. - Contributions to an insect fauna of the Amazon Valley. Lepidoptera: Heliconidac. Trans. Linn. Soc., Zool., 23: 495-566, 1862.

8. BRAUN, M. \& LOHE, M. - A Handbook of Practical Parasitology, John Bale, Sons, and Danielson Ltda., Londres, 1910.

9. CARTER, G.S. - Animal Evolution: A Study of Recent Views of Its Causes. Sidewick \& Jackson Ltda., Londres, 1951.

10. CHAPMAN, R.N. - Animal Ecology, With Special Reference to Insects. McGraw-Hill, N. York e Londres, 1931.

11. CLEMENS, F. E. \& SHELFORD, V. E. Bio-ecology - John Wiley \& Sons, N. Ycrk (1949), 1939.

12. CROMPTON, D.W.T. - The sites occupied by some parasitic helminths in the alimentary tract of vertebratesu. Biol, Rev., 48: 27-83, Londres e N. York, 1973.
13. D'ANCONA, U. - The Struggle for Existence. Biblioteca Biotheretica, D, 4, E.J. Brill, Leiden, 1954.

14. DARWIN, $\mathrm{C}$ - - On the Origin of Species by Means of Natural Selection, or the Preservation of Favored Races in the Struggle for Life. Murray, Londres, 1859.

15. DARWIN, C. \& WALLACE, A.R. Evnlution by Natural Solection. Cambridge University Press, Londres, 1958.

16. DOBZHANSKY, T. - Genetics and the Origin of Species. Columbia Univirsity Presss, N. York, 1937.

17. DUBOS, R. - Man Adapting. Yale University Press. N. Haven e Londres, 1965 .

18. DUBOS, R. \& SCHAEDLER, R.W. The digestive tract as en ecosystem. Amer. J. Med. Sci., 248: 267-271, 1964.

19. DUBOS, R., SCHAEDLER R., COSTFLLO, R.L. \& HOLT, D - indigeneous, normal, and autochthonous flora of the gastrointestinal tract. $J$. Exptl. Med., 122: 67-76, 1965.

20. DUBOST, G. - Les niches ecologiques des forets tropicales Sud-Américaines et Africaines, source de convergences remarquables entre rongeurs at artiodactyles. J.a Terre et la Vie, 22: 3-28, Paris, 1968.

21. ELTON, C. - Animnl Ecolnay. Sidgwick \& Jackson, Ltda:, Londres, 1927.

22. ESPINAS, A. - Des Sociétes Animales. G. E. Stiechert \& Co., N. York, 1878.

23. FISCHER, R.A. - The Genetical Thoory of Natural Selection. 2nd. ed., Dover, N. York, 1958.

24. FORBES, E. - Report on the Molluscs and Radiata of the Aegean Sea, and on their distribution considered as bearing on Geology. Rept. $B r . A$. Adv. Sc., 13: 130-193, Londres, 1943 , reimpresso em KORMONDY, E. J. - Readings in Ecology. Prentice Hall Inc., N. Jersey; 1965. 
25. FORBES, E. - On the light thrown on geology by submarine researches. Edinb. New. Philos. J., 36: 318-317, 1844.

26. FORBES, S. A. - The lake as microcosm. Bull. Soc. A. Peoria, reimpresso in KORMONDY, E. J. Readings in Ecology, Princeton Hall Inc., N. Jersey, 1965.

27. GALUZO, I.G. - Twenty years of natural-nidal disease studies. In LEVINE, N.D., ed., Natural Nidality of Diseases and Questions of Parasitology: 9-15. Trad. Proc. IV Conference on the Natural Nidality of Diseases and Questions of Parasitology of Kazakhstan and the Republics of Middle Asia, 15-20 September, 1959, Alma-Ata, URSS, UUUniversity of Illinois Press, Urbana, 1968.

28. GEIGER, R. - The Climate Near the Ground. Harvard University Press, Cambridge, Mass, 1950.

29. GILMOUR, J. S. \& GREGOR, J. W. Demes: a suggested new terminology. Nature, 144: 333, 1939.

30. GOLVAN, Y. J. \& ROUX, J.A. - Écologie des Mérions du Kurdistan Iranien Relations avec l'épidémiologie de la peste rurale. Ann. Parasit. Hum. Ccmp. 36: 449-588, 1961.

31. GRANT, V. - The Origin of Adaptations. Columbia University Press, N. York e Londres, 1963.

32. HAECKEL, E. - Generelle Morphologie der Organismen. 2 vols. G. Reimer, Berlim, 1866.

33. HAECKEL, E. - Natürlische Schopfungsgeschichte. G Reimer. Berlim, 1868.

34. HERSHKOVITZ, P. - A Geographic classification of Neotropical Mammals. Fieldiana, Zool. Nat. Hist. Mus, , 36: $583-62,0,1958$.

35. HUXLEY, J. - Evolution - The Modern Synthesis. G. Allen \& Unwin Ltd., Londres, 1942.

36. JEPSEN, G.L., SIMPSON, G. G. \& MAYR, F. - Genetics, Paleantology and Evolution. Princeton University Press, N. Jersey, 1949.

37. LAMARCK, J.B.M. - Discours D'Ouverture, $A n$ VIII (1800), An $X$ (1802), An $X I$ (1803) e 1806. Bull. Sci. France ret Belgique, 40: 1907.

38. LAMARCK, J.B.M. - Philosophie Zoologique. C. Reiwald, Paris, 1809.
39. MALTHUS, T.R. - Essay on the Principle of Population, or $A$ View of Its Past and Present Effects on Human Happiness. Londres. Reimpr. in Kormondy. E. J., Readings in Ecology, 1965 .

40. MALTHUS, T.R. - Ensayo sobre el Principio de la Población. Trad. Teodoro Ortiz, 7.a ed., Fondo de Cultura Económica, México - Buenos Aires, 1951 .

41. MARPLES, M.J. - The ecology of the human skin. Thomas springfield, 1965.

42. MAYR, E. - Systematic and the oribin of Species. Columbia Universityx, Pres, 1942.

43. MEGGERS, B.J., AYENSU, E. \& DUCKWORTH W.D., - Tropical Ecosystems in Africa and South America: A Comparative Review. Smithsonian Press, Washington, D.C., 1972.

44. MELLO-LEITÃO, C., - Zoogeografia do Brasil. Brasiliana, 2a ed., Cia. Ed. Nac., São Paulo, 1947.

45. MENDEL, G. - Versuche über Pflanzen-Hybriden. Verh. Naturforsch. Verein Brün, 4: 3-47. Trad. e reimp. em SINNOTT, E.L.C. DUNN e T. DOBZHANSKY, 1950, Principles of Genetics, McGraw-Hill, N. York e Londres.

46. METCALF, M.M. - Parasites and the aid they give in problems of taxonomy, gecgraphical distribution, and paleogeography. Smithson. Misc. Coll., 81: 1-36, Washington, D.C., 1929.

47. MOBIUS, K., 1877 - Die Axster und die Austernwirtschaft. Wiegundt, Hempel \& Parey, Berlim. Traduzido e reimpresso em KORMONDY, E.J., 1965. Readings in Ecology. Prentice -Hall, Inc., N. Jersey.

48. NEUMAN, L. G. D. - Traite des Maladies Parasitaires Non-microbiennes des Animaux Domestiques. 2a ed., Asselin \& Houzeau, Paris. 1892.

49: ORGANIZATION MONDIAL DE LA SANTÉ - Technical Guide for a system of plague surveillance. WHO Wkly. Epitem. Rec., 14: 149-160, 1973.

50. PAVLOVSKY, E.N., s/d. - Natural Nidality of Transmissible Diseases. Trad. Yuri Shirokov, Peace Pul., Moscou.

5i. PLATT, R. B. \& GRIFFTHS, J . Environmental Measurement and Interpretation. Van Nostrand Reinhold Co., N. York, 1964. 
52. PREMIER SYMPOSIUM SUR LA SPECIFICITÉ PARASITAIRE DAS PARASITES DE VRTEBRES. Instituto de Zoologie de Neuchâtel, 1957.

53. RABAUD, F. - Phénomène Social et Sociétés Animales. Félix Alcan, Paris, 1937.

54. RENSCH B. - Evolution Above the Species Level. Methuen \& Co. Ltd., Londres, 1959.

55. SACK, R.B. - The ecology of the gastrointestinal tract. In SLADEN, B.K. e F.B. BANG, esc. Biology of Populations. The Biological Basis of Public Health. Elsevier, N. York, 1969 .

57. SCHROTER, C. \& KIRCHNER, O. Die Vegetation des Bodensees. Schriften Ver. fesch. Bodensees Umgeb. 25: 1-119, e 31: 1-80, 1895 e 1902.

58. SHELFORD, M. B. - Animal Communities in Temperate America. Bull. Geogr. Soc. Chicago, 5. Reimpresso em 1937, pela University of Chicago Press, 1913

59. SINGER, C. - From Magic to Cience. Dover, N. York, 1958.

60. SIMPSON, G. G. - Tempo and Mode in Evolution. Columbia University Press. N. York. Reeditado atua- lizado como The Major Features in Evolution, 1953, Columbia University Press.

61. SIMPSON, G. G. Evolution and Geography. Eugene, Oregino, 1953.

62. STALLONES, R. A. - El Ambiente, la Ecologia y la Epidemiologia. $4 .^{a}$. Confer. OPS/OMS, Ciencias Biomédicas, Publ. Ci. 231 OPS/OMS, Washington, D.C., 1971.

63. STEBBINS, Jr., G. L. - Variation and Evolution in Plants. Columbia Biological Series, 16, Columbia University Press, N. York, 1950.

64. SUTTON, O. G. - Micrometeorology. McGraw-Hill, N. York, 1953.

65. UNESCO - Functioning of Terrestrial Ecosystems at the Primary Production Level. Proc. Copenhagen Symposium, F.E. ECKARDT, ed., Paris.

66. WALLACE, A. R. - Natural Selection and Tropical Nature. Macmillan Co., Londres, 1891.

67. WALLACE, A. A. - The World of Life. G. Bell \& Sons, Londres, 1911.

68. WRIGHT, S. - Evolution in Mendelian populations. Genetics. 15: 323$-354,1931$. 